\section{Positive behavioral contrast with qualitatively different reinforcing stimuli*}

\author{
RICHARD J. BENINGER \\ University of Western Ontario, London, Ont., Canada
}

Four hooded rats were placed on a mult VI 30 VR 3.3 schedule in which food was used to reinforce responding in the VI 30 component and electrical stimulation of the brain (ESB) was used to maintain behavior in the VR 3.3 component. When the VR 3.3 was switched to extinction, there was a positive behavioral contrast effect in the VI 30 component. These results supported the hypothesis that there would be an interaction between components in which qualitatively different reinforcing stimuli are used.

The rate of responding in one component of a multiple schedule (Ferster \& Skinner, 1957) may be altered by manipulating conditions in the alternate component. One such component interaction is termed behavioral contrast (Reynolds, 1961). An increase in the rate of responding in one component of a multiple schedule, which occurs when the response rate in another component is decreased or when the other component is replaced by conditions controlling a lower response rate, is defined as positive behavioral contrast. Negative behavioral contrast is defined as a decrease in response rate in the presence of one stimulus as a function of an increase in the response rate associated with another stimulus.

Most of the experiments that deal with the interaction of components in a multiple schedule employ the same reinforcing stimulus to maintain behavior in all of the components or alternate extinction with a component in which a reinforcing stimulus is used (see Freeman, 1971). A few experimenters, however, have used different reinforcing stimuli in the alternate components of a multiple schedule. Herrnstein \& Brady (1958) trained rats on a multiple schedule consisting of a fixed interval for food reinforcement, a period of $S \Delta$, an avoidance component, and another period of $S \Delta$ in order to investigate possible interactions among components. They found that variations in the shock-shock interval produced not only changes in the rate of avoidance responding, but also changes in the rate of responding during both $\mathrm{S} \Delta$ periods. Premack

*This study was supported in part by National Research Council of Canada Grant APB-118 to Dr. C. H. Vanderwolf. Grateful acknowledgement is due to Drs. S. B. Kendall and C. H. Vanderwolf for their valuable criticism in the execution of the research and the writing of the manuscript. The author also wishes to thank M. Cole and Dr. F. M. VanFleet for their guidance in the laboratory.
(1969) presented rats with a mult VI 30 -sec schedule in which reinforcement in one component was a $3-\mathrm{sec}$ presentation of a drinkometer and reinforcement in the alternate component consisted of $3 \mathrm{sec}$ of running in an activity wheel. When the component in which responding was reinforced with activity wheel running was changed to an extinction condition, positive behavioral contrast was observed in the alternate component. The results of both Herrnstein \& Brady's (1958) study and Premack's (1969) study seem to show that the interactions found to occur between components of a multiple schedule do not depend on the similarity of reinforcers used to maintain behavior.

The purpose of the present study was to investigate further the effects of different reinforcers on the interaction of components in a multiple schedule. Unilateral electrical stimulation of the lateral hypothalamus and food were the reinforcers used in the two components of the multiple schedule. On the basis of the results of Premack's (1969) experiment, it was predicted that positive behavioral contrast would occur when the component, in which electrical stimulation of the brain was the reinforcer, was changed to an extinction condition.

\section{SUBJECTS}

Four experimentally naive male black hooded rats, approximately 4 months of age, were maintained at $80 \% \pm 2.5 \%$ of their free-feeding body weights throughout the experiment.

\section{APPARATUS}

The experimental chamber used was manufactured by the Lehigh Valley Electronics Co. (Model 143-24). It was modified so that there was just one lever and no cue lights. The chamber box, lighted by a lamp, ventilated by a small fan, and provided with constant masking noise. The stimulating leads, was enclosed in a sound-attenuating attached to a mercury commutator mounted atop the sound-attenuating box, extended through holes in the top of the box and the chamber. This arrangement allowed the rats freedom of movement. A Grass S6 stimulator was used to deliver electrical stimulation of the brain (ESB) consisting of square-wave biphasic trains of $.85-\mathrm{msec}$ pulses and $100-\mathrm{Hz}$ frequency. The train duration was $0.5 \mathrm{sec}$. The voltage employed varied from rat to rat and ranged from 4.5 to $6.0 \mathrm{~V}$.

Electromechanical switching devices located in an adjacent room were used to program the contingencies. Data were recorded on elapsed time meters, counters, and a cumulative recorder. SURGERY

After anesthetization with IP injection of $50 \mathrm{mg} / \mathrm{kg} \mathrm{Nembutal}$ and a small dose $(2 \mathrm{cc})$ of atropine sulfate, one Plastic Products bipolar electrode made of stainless steel wires $0.01 \mathrm{in}$. in diam was stereotaxically implanted in each rat. Level skull coordinates of $2.8 \mathrm{~mm}$ posterior to bregma, $1.5 \mathrm{~mm}$ lateral to the midline, and $8.3 \mathrm{~mm}$ below the skull were used with the lateral hypothalamus as the target. All rats were given at least 8 days for recovery before training procedures were begun.

\section{PROCEDURE}

For all rats, a leverpress response was shaped with reinforcement consisting of a 5-sec dipper presentation of $1 \mathrm{cc}$ of Nestle's sweetened condensed milk mixed in 1:1 proportion by weight with water. After shaping, the rats received at least one session of CRF training and one session of VI 30-sec training, followed by training on a mult VI 30 -sec (food) VR 3.3 (ESB) schedule of reinforcement. Since ESB was used to reinforce the same operant as food, the rats all made some responses when the VR component was switched into effect. Voltage was then adjusted to a level that maintained behavior. The houselight was illuminated during the VI 30 (food) component and remained off during the VR 3.3 (ESB) component. Each component remained in effect for $2 \mathrm{~min}$, after which it was automatically switched to the alternate component. Daily sessions consisted of 10 cycles (i.e., 10 VIs and $10 \mathrm{VRs}, 40 \mathrm{~min}$ ).

When responding had stabilized (i.e., showed no trend for 5 consecutive days), the schedule was switched to mult VI 30 (food) EXT (extinction). A 10-sec changeover delay (COD) was utilized at the end of the EXT component in order to prevent superstitious chaining. The rats were then given an additional 10 days of training on the mult VI 30 (food) VR 3.3 (ESB) schedule. 


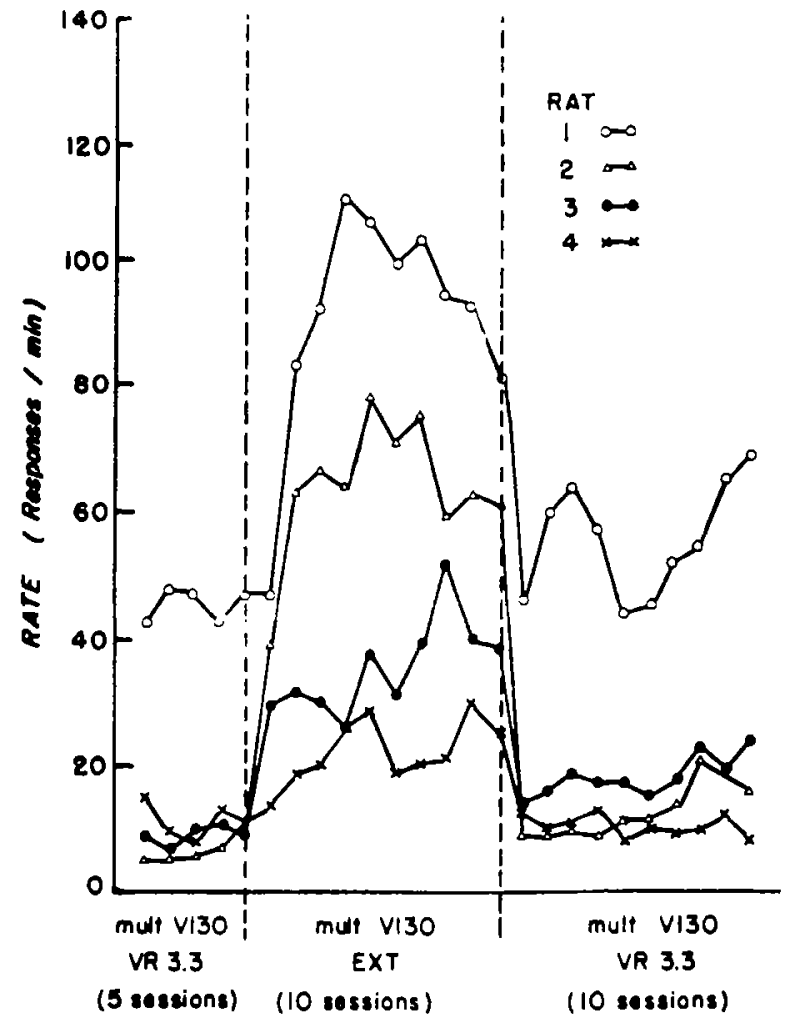
Fits.

ig. 1. Response rates in the VI 30 component for all

\section{RESULTS}

Response rate data taken across the last 5 mult VI 30 VR 3.3 sessions, the 10 mult VI 30 EXT sessions, and the additional mult VI 30 VR 3.3 sessions in the VI 30 component for the four rats are presented in Fig. 1 and the response rate data taken across these sessions in the VR 3.3 (or EXT) component are presented in Fig. 2. Each point represents the response rate during the VI 30 or VR 3.3 component for one daily session.

For all rats, the response rates during the VI 30 component increased above the baseline rates when the mult VI 30 VR 3.3 was switched to mult VI 30 EXT. When the mult VI 30 VR 3.3 was switched back into effect, VI 30 rates returned to their baseline level. With the exception of two sessions-the first day of mult VI 30 EXT for Rat 1 and the first day for Rat 4 -none of the VI 30 response rates during mult VI 30 EXT were as low as or lower than any of the VI 30 response rates during mult VI 30 VR 3.3 for an individual rat. These results, then, are a clear example of the occurrence of positive behavioral contrast.

During the extinction of the VR 3.3 component, the response rates in the component dropped almost

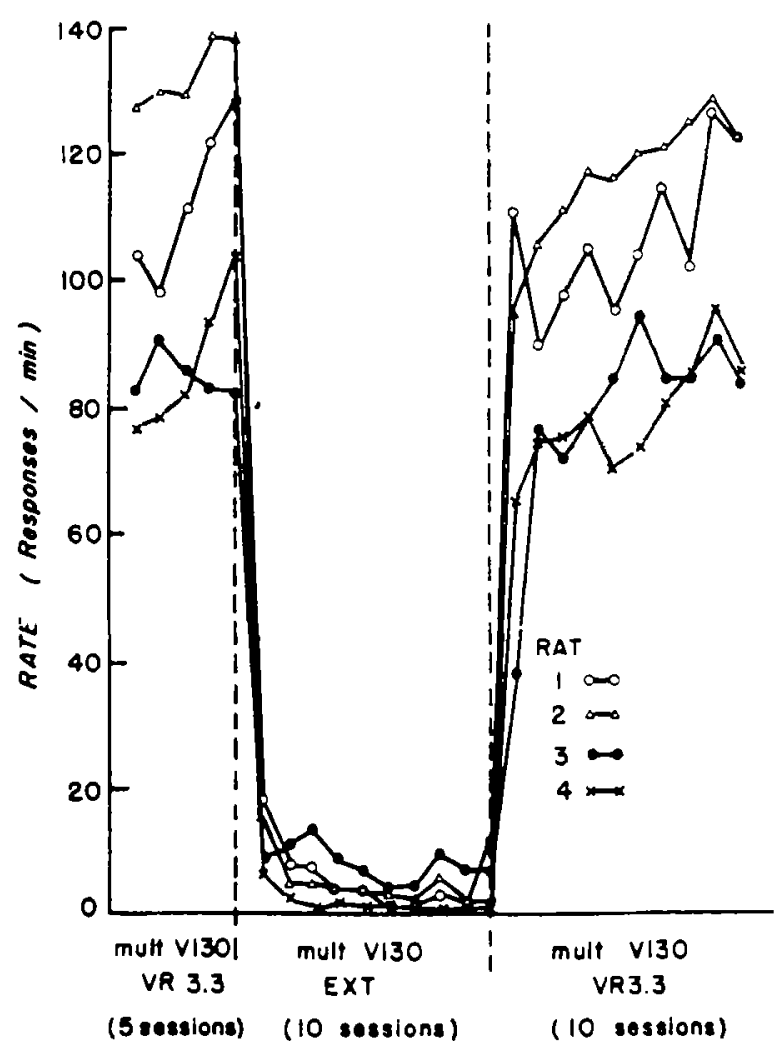

Fig. 2. Response rates in the VR 3.3 (or EXT) component for all rats. immediately from between 80 and 138 responses/min to less than 20 responses $/ \mathrm{min}$ and remained at a low level until ESB was again made available. When the mult VI 30 VR 3.3 was switched back into effect, response rates in the VR 3.3 component returned to their baseline levels for all rats.

\section{DISCUSSION}

The results of the present study indicate that positive behavioral contrast does occur with qualitatively different reinforcing stimuli in the two components of a multiple schedule. Premack (1969) found an interaction between the behaviors in the components of a multiple schedule when the reinforcing stimuli were a 3-sec presentation of a drinkometer in one component and $3 \mathrm{sec}$ of activity wheel running in the other. The results of the present experiment suggest that Premack's (1969) findings can be generalized to cases in which a different set of different reinforcing stimuli are used in the components of a multiple schedule.

Catania (1966) studied interactions between concurrently programmed schedules in which responses were reinforced with appetitive stimuli or avoidance. The results showed that removal of either concurrent schedule did not systematically produce increases in the rate of responding maintained by the other schedule. He suggested the possibility that interactions found to occur between schedules presented concurrently may depend on the similarity of reinforcers used to maintain behavior in the different schedules. The results of this experiment, although generated by a multiple schedule, would suggest that behaviors maintained by different reinforcers do interact.

\section{REFERENCES}

CATANIA, A. C. Concurrent operants. In W. K. Honig (Ed.), Operant behavior: A reas of research and application. New York: A ppleton-Century-Crofts, 1966.

FERSTER, C. B., \& SKINNER, B. F Schedules of reinforcement. New York: A ppleton-Century-Crofts, 1957.

FREEMAN, B. J. Behavioral contrast: Reinforcement frequency or response suppression? Psychological Bulletin. $1971,75,347-356$

HERRNSTEIN, R. J., \& BRADY, J. V. Interaction among components of a multiple schedule. Journal of the Experimental Analysis of Behavior, 1958. 1. 293-300.

PREMACK, D. On boundary conditions of contrast. In J. T. Tapp (Ed.), Reinforcement and behavior. New York: Academic Press, 1969. Pp. 120-145.

REYNOLDS, G. S. Behavioral contrast. Journal of the Experimental Analysis of Behavior, 1961, 4, 57-71. 